\title{
Validation of the Korean version of the Standardized Cosmesis and Health Nasal Outcomes Survey
}

\author{
Woo Ri Choi ${ }^{1}$, Shin Ae Kim², Sung Hee Kim³, and Yong Ju Jang ${ }^{4} \mathbb{C}$ \\ ${ }^{1}$ Department of Otorhinolaryngology-Head and Neck Surgery, Samsung Changwon Hospital, Sungkyunkwan University \\ School of Medicine, Changwon; and \\ ${ }^{2}$ Department of Otolaryngology-Head and Neck Surgery, Soonchunhyang University Seoul Hospital, Soonchunhyang University \\ College of Medicine, Seoul; and \\ ${ }^{3}$ Department of Otorhinolaryngology-Head and Neck Surgery, National Medical Center, Seoul; and \\ ${ }^{4}$ Department of Otorhinolaryngology-Head and Neck Surgery, Asan Medical Center, University of Ulsan College of Medicine, Seoul, Korea
}

\author{
한국어 버전 Standardized Cosmesis and Health Nasal Outcomes Survey의 \\ 타당도 및 신뢰도 검증 \\ 최우리 ${ }^{1} \cdot$ 김신애 $^{2} \cdot$ 김성희 $^{3} \cdot$ 장용주 $^{4}$ \\ 성균관대학교 의과대학 삼성창원병원 이비인후-두경부외과학교실, \\ 순천향대학교 의과대학 서울순천향대학병원 이비인후-두경부외과학교실, ${ }^{2}$ 국립중앙의료원 이비인후과, \\ 울산대학교 의과대학 서울아산병원 이비인후-두경부외과학교실 ${ }^{4}$
}

\author{
Received August 5, 2019 \\ Accepted January 2, 2020 \\ Address for correspondence \\ Yong Ju Jang, MD, PhD \\ Department of Otorhinolaryngology- \\ Head and Neck Surgery, \\ Asan Medical Center, \\ University of Ulsan \\ College of Medicine, \\ 88 Olympic-ro 43-gil, Songpa-gu, \\ Seoul 05505, Korea \\ Tel $+82-2-3010-3710$ \\ Fax $+82-2-489-2773$ \\ E-mail jangyj@amc.seoul.kr
}

Background and Objectives The 10-item Standardized Cosmesis and Health Nasal Outcomes Survey (SCHNOS) is a recently developed questionnaire for assessing both nasal obstruction and nasal cosmetic satisfaction. It is widely used in rhinoplasty clinics based on its high level of reliability and efficacy in Western countries. In this study we evaluated the validity of the Korean version of the SCHNOS (K-SCHNOS).

Subjects and Method The SCHNOS was translated into easily-understandable Korean following the guideline of the developers. Twenty-seven patients undergoing rhinoplasty and a control group of 29 non-rhinoplasty patients completed K-SCHNOS twice at intervals of 2 weeks regardless of pre- or postoperative state. The K-SCHNOS was evaluated for internal consistency, test-retest reliability, and validity.

Results Of the 56 study participants, 39 (69.6\%) were male and 17 (30.4\%) were female, with the mean (standard deviation) age of 33.5 (12.9) years. Both obstructive domain and cosmetic domains showed high internal consistency with their respective Cronbach' $\alpha$ values being 0.92 and 0.91 . The correlations in the test-retest analysis for each item were acceptable, ranging from $0.6-0.82$. The association between the obstructive domain and cosmetic domain was 0.48 (95\% confidence interval, $0.32-0.61$ ), indicating a very weak correlation.

Conclusion The K-SCHNOS has proven to be a reliable and valid questionnaire to be used by Korean-speaking patients undergoing functional or cosmetic rhinoplasty. Korean J Otorhinolaryngol-Head Neck Surg 2020;63(4):163-6

Key Words Questionnaire · Rhinoplasty $\cdot$ SCHNOS. 
하는 것도 중요하지만, 환자의 주관적인 느낌과 증상의 변화 를 정확히 파악하는 것이 무엇보다 중요한 요소라고 할 수 있겠다. 특히 수술 전 환자의 코 모양에 대한 불만족의 정도 와 미적 기준에 대한 파악은 의사가 수술 방법을 계획할 때 많은 도움이 될 것으로 생각한다. 환자의 주관적 코막힘을 평 가하는 질문으로는 Visual Analogue Scale, Nasal Obstruction Symptom Evaluation, Sino Nasal Assessment Questionnaire-22 등 몇 가지 방법들이 있지만 위의 설문들은 미 용적 만족도는 반영하지 않고 있다. ${ }^{1,2)}$ 코와 얼굴의 미용적 측 면을 평가하는 설문지로는 FACE-Q, Rhinoplasty Outcome Evaluation 등이 있지만 코의 기능적 측면에 대한 부분은 충분 히 반영하지 않고 있다. ${ }^{3,4}$ Standardized Cosmesis and Health Nasal Outcomes Survey(SCHNOS)는 최근에 Moubayed 등ㄱㅇㅔ 의해 개발되었으며, 코막힘과 미용적 불만족 정도를 모두 파악하기 위한 도구로 사용되고 있다. 이 설문지는 아라 비아, 페르시아, 프랑스, 스페인 등 여러 나라의 언어로 번역 되었고 각 나라에서 후속 연구에 의해서 그 타당성이 입증되 었다. ${ }^{6-9)} \mathrm{SCHNOS}$ 는 또한 짧고 이해하기 쉬운 10 가지 문항 으로 구성되어 있어 외래에서 작성하기 용이하며 코 성형수 술 전 선별 검사(screening)와 수술 후 평가에 적합하다. 따라 서 본 연구에서는 한국어 버전 SCHNOS의 검사 도구로서의 타당도를 검증해 보고자 한다.

\section{대상 및 방법}

SCHNOS는 기능 척도(functional scale) 4문항과 미용 척 도(cosmetic scale) 6 문항으로 이루어져 있으며 각 문항은 "전 혀 문제 없음"에 해당하는 0 점부터 “매우 문제 있음"에 해당 하는 5점까지 6단계로 점수를 매기도록 되어 있다. 설문지의 1 차 번역은 이비인후과 전문의 2 인에 의해 시행되었다. 독립적 으로 번역된 두 가지 버전의 한국어 SCHNOS(Korean version of the SCHNOS, K-SCHNOS)는 팀의 또 다른 전문의에 의해 통합된 이후 영어로 역번역되었으며 최종적으로 $\mathrm{SCH}-$ NOS의 개발자인 스탠포드 대학의 Sam P. Most에게 전달되 어 원문과 의미가 달라지거나 혼란을 주는 부분이 있는지 검 토되었다(Fig. 1).

본 연구는 2018년 1월 2019년 7월까지 본원 이비인후과 외 래에 내원한 환자를 대상으로 시행되었으며 본원 임상연구심 의위원회(Institutional Review Board)의 승인을 얻었다(IRB No. 2019-1048). 연구대상자의 선별과 실험의 과정들은 개 발자들이 제시한 가이드라인대로 이루어졌다. 나이가 18세 이하이거나 한국어를 이해하지 못하는 환자들은 제외되었으 며 총 27 명의 코 성형 환자들과 29 명의 대조군이 연구에 포

\begin{tabular}{|c|c|c|c|c|c|c|}
\hline \multicolumn{7}{|c|}{ During past 1 month, how much were you troubled with following items? } \\
\hline & \multicolumn{2}{|c|}{$\begin{array}{l}\text { No problem } \\
\text { at all }\end{array}$} & \multirow[b]{2}{*}{2} & \multirow[b]{2}{*}{3} & \multicolumn{2}{|c|}{$\begin{array}{c}\text { Severely } \\
\text { problematic }\end{array}$} \\
\hline $\begin{array}{l}\text { 1. Experienced totally blocked } \\
\text { sensation }\end{array}$ & 0 & 1 & & & 4 & 5 \\
\hline $\begin{array}{l}\text { 2. Difficult nasal breathing } \\
\text { while exercising }\end{array}$ & 0 & 1 & 2 & 3 & 4 & 5 \\
\hline $\begin{array}{l}\text { 3. Uncomfortably obstructed } \\
\text { nasal breathing }\end{array}$ & 0 & 1 & 2 & 3 & 4 & 5 \\
\hline 4. Nasal breathing during sleep & 0 & 1 & 2 & 3 & 4 & 5 \\
\hline $\begin{array}{l}\text { 5. Feel unhappy and depressed } \\
\text { because of the nasal shape }\end{array}$ & 0 & 1 & 2 & 3 & 4 & 5 \\
\hline 6. Shape of the nasal tip & 0 & 1 & 2 & 3 & 4 & 5 \\
\hline $\begin{array}{l}\text { 7. Nose looks straight from } \\
\text { the frontal }\end{array}$ & 0 & 1 & 2 & 3 & 4 & 5 \\
\hline 8. Side view of profile view of nose & 0 & 1 & 2 & 3 & 4 & 5 \\
\hline $\begin{array}{l}\text { 9. Nose is in good harmony with } \\
\text { my face }\end{array}$ & 0 & 1 & 2 & 3 & 4 & 5 \\
\hline 10. Overall symmetry of my nose & 0 & 1 & 2 & 3 & 4 & $5 \mathbf{A}$ \\
\hline
\end{tabular}

지난 한달 간, 다음의 각 항목이 본인에게 얼마나 문제가 되었습니까?

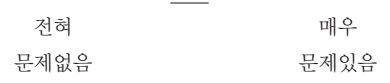

$\begin{array}{llllllll}\text { 1. 코가 꽉 막힌 적이 있다 } & 0 & 1 & 2 & 3 & 4 & 5 & \\ \text { 2. 운동할 때 코로 숨쉬기 } & 0 & 1 & 2 & 3 & 4 & 5 & \\ \text { 3. 코로 호흡하기 답답함 } & 0 & 1 & 2 & 3 & 4 & 5 & \\ \text { 4. 수면시 코로 호흡하는 것 } & 0 & 1 & 2 & 3 & 4 & 5 & \\ \text { 5. 코로 인해 기분이 나쁘고 } & 0 & 1 & 2 & 3 & 4 & 5 & \\ \quad \text { 자존감이 떨어짐 } & & & & & & & \\ \text { 6. 코끝의 모양 } & 0 & 1 & 2 & 3 & 4 & 5 & \\ \text { 7. 정면에서 볼 때 코가 똑바르다 } & 0 & 1 & 2 & 3 & 4 & 5 & \\ \text { 8. 옆에서 본 코의 모습 } & 0 & 1 & 2 & 3 & 4 & 5 & \\ \text { 9. 코가 나의 얼굴과 잘 조화가 되는가 } & 0 & 1 & 2 & 3 & 4 & 5 & \\ \text { 10. 코의 전체적인 대칭성 } & 0 & 1 & 2 & 3 & 4 & 5 & \text { B }\end{array}$

Fig. 1. Original English version of Standardized Cosmesis and Heath Nasal Outcomes Survey (A). Korean version of Standardized Cosmesis and Health Nasal Outcomes Survey (B).

함되었다. 대조군은 비중격 만곡증 환자 21명, 만성 부비동염 환자 6명, 알레르기 비염 환자 2명으로 이루어졌다. 연구에 포함된 환자들은 모두 수술 전후에 관계없이 2주 이상의 간 격으로 2회에 걸쳐서 설문을 시행하였고 이중 무작위로 10 명을 선정하여 $\mathrm{K}-\mathrm{SCHNOS}$ 의 10 가지 질문이 모두 명확하게 이해되었는가에 대해 15 분씩 면담하였다. 코 성형군과 대조 군 간의 점수 차이를 확인하기 위해 2-sample Wilcoxon rank sum test가 사용되었으며 두 군 간 기능 척도와 미용 척 도 각각의 총점의 차이가 있는지 알아보기 위해 2-tailed $p$ value를 계산하여 0.05 이하를 유의미한 것으로 보았다. $\mathrm{K}-$ SCHNOS의 신뢰도는 문항의 내적 일치도(internal consistency)와 검사-재검사 신뢰도(test-retest reliability)를 통해 검증하였으며 Spearman rank correlation과 Pearson correlation coefficient를 이용하여 상관계수를 계산하였다. 자료 분석을 위해 모든 통계 분석은 SPSS version 22.0(IBM 
Table 1. Association between rhinoplasty group and non-rhinoplasty group

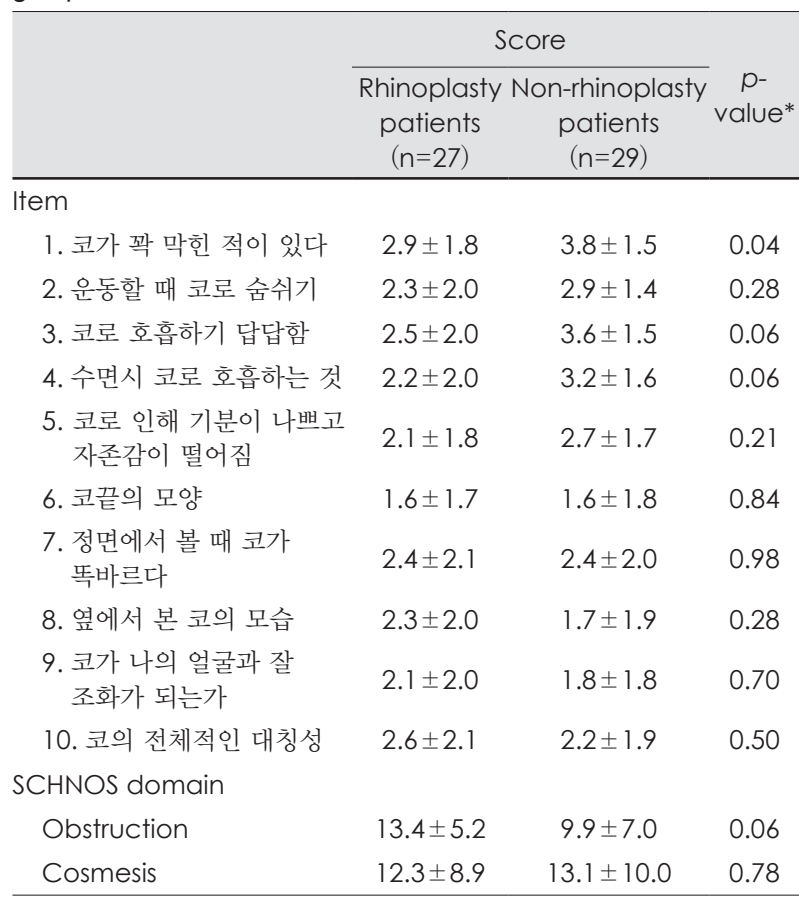

Data are presented as mean \pm standard deviation. $* 2$-sample Wilcoxon rank sum test. SCHNOS: Standardized Cosmesis and Health Nasal Outcomes Survey

Corp., Armonk, NY, USA)를 사용하였다.

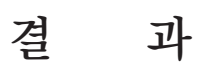

코 성형군 27명 중 18명(67\%)이 남자, 9명(33\%)이 여자였고 대조군 29명 중 21명(72\%)이 남자, 8 명(28\%)이 여자였다. 평 균 나이는 코 성형군이 $30.5 \pm 10.9$ 세 , 대조군이 $36.8 \pm 15.0$ 세 로 두 군 간 유의한 차이가 없었다. $\mathrm{K}-\mathrm{SCHNOS} 10$ 개 문항의 명확성에 대해 면담자 10 명 모두가 질문의 뜻이 명확하게 이 해된다고 답하였다.

코 성형군과 대조군 간의 비교에서는 1 번 문항을 제외한 나머지 문항에서 모두 $p>0.05$ 로 차이가 없는 것으로 나타났 다(Table 1). 기능 척도의 총점끼리 비교했을 때와 미용 척도 의 총점끼리 비교했을 때 또한 두 군 간 차이는 드러나지 않 았다. K-SCHNOS 기능 척도의 Cronbach's $\alpha$ 는 0.92 , 미용 척도의 Cronbach's $\alpha$ 는 0.91로 역시 각 하위 측정 영역이 동 질적인 구성 개념을 측정하는 것으로 나타났다. $\mathrm{K}-\mathrm{SCHNOS}$ 총점 및 각 문항의 검사-재검사 신뢰도는 0.6 0.82 사이로 모 든 문항에서 중등도 이상의 연관성을 보여주었다(Table 2). 기 능 척도와 미용 척도 간의 상관계수는 $0.48(95 \%$ confidence interval, 0.32 0.61)로, 두 척도 간의 일치도는 매우 약하다는 것을 알 수 있었다.
Table 2. Correlation between 2 repeated measures of the Korean SCHNOS

\begin{tabular}{lc}
\hline Item & $\begin{array}{c}\text { Correlation coefficient } \\
(95 \% \text { Cl) }\end{array}$ \\
1. 코가 꽉 막힌 적이 있다 & $0.74(0.59-0.84)$ \\
2. 운동할 때 코로 숨쉬기 & $0.74(0.59-0.84)$ \\
3. 코로 호흡하기 답답함 & $0.73(0.58-0.83)$ \\
4. 수면시 코로 호흡하는 것 & $0.78(0.66-0.87)$ \\
5. 코로 인해 기분이 나쁘고 & $0.82(0.71-0.89)$ \\
자존감이 떨어짐 & $0.67(0.49-0.79)$ \\
6. 코끝의 모양 & $0.60(0.34-0.71)$ \\
7. 정면에서 볼 때 코가 똑바르다 & $0.63(0.44-0.77)$ \\
8. 옆에서 본 코의 모습 & $0.75(0.61-0.85)$ \\
9. 코가 나의 얼굴과 잘 조화가 되는가 & $0.60(0.40-0.75)$ \\
10. 코의 전체적인 대칭성 & \\
SCHNOS domain & $0.77(0.64-0.86)$ \\
Obstruction & $0.71(0.55-0.82)$ \\
Cosmesis &
\end{tabular}

SCHNOS: Standardized Cosmesis and Health Nasal Outcomes Survey, $\mathrm{Cl}$ : confidence interval

\section{고 찰}

코 성형수술에 있어 환자의 기능적, 미용적 욕구를 동시에 적절하게 반영하는 것은 매우 어려우면서도 중요한 문제이 다. 이를 위해 수술 전 내시경 검사, 비강통기도 검사, 안면 전산화단층촬영 검사 등 기능적 문제를 파악하기 위한 다양 한 검사들이 이루어지고 시뮬레이션을 통해 환자의 미용적 요구에 수렴하기 위해 노력하지만 그럼에도 불구하고 환자들 의 기대와 의사들이 생각하는 실제 수술의 결과와는 차이가 있을 수 있다. 한편 현대 의료가 질병중심적 성격에서 환자 중심, 소비자중심, 개인별 맞춤화 개념으로 이동함에 따라 미용수술에서뿐만 아니라 많은 질병의 치료에서 환자 스스 로 보고하는 설문 체계(patient-reported outcome measure) 의 중요성과 유용성이 대두되고 있다. ${ }^{10)}$ 따라서 본 연구에서 는 코 성형 환자들을 대상으로 하는 기능과 미용에 대한 통 합 설문지를 국내에 도입하여 코 성형수술 전 목표 설정 시 환자와의 간격을 좁히고 수술 후 환자 만족도를 높이는 데 기여하고자 하였다. 연구 결과 $\mathrm{K}-\mathrm{SCHNOS}$ 는 높은 신뢰도 및 타당도를 지니고 있는 것으로 나타났다. K-SCHNOS의 Cronbach's $\alpha$ 는 기능 척도에서 0.92, 미용 척도에서 0.91로 영 어, 아랍어, 페르시아어, 스페인어, 프랑스어 버전 SCHNOS 연구에서 기능과 미용척도의 Cronbach's $\alpha$ 가 0.94와 0.94, 0.86 과 $0.89,0.82$ 와 $0.88,0.84$ 와 $0.94,0.93$ 과 0.94 였던 것과 비교해 보아도 높은 수준의 내적 일치도를 보임을 알 수 있 다. ${ }^{5-9)}$ 그러나 코 성형군과 대조군 간의 비교에서 의미 있는 
차이를 보였던 국외 문헌들에 반해 본 연구에서는 두 그룹 간 기능 척도와 미용 척도의 점수 모두 통계적으로 유의한 차 이가 없었다. 이에 대해 대조군의 $70 \%$ 가 비중격 만곡증 환 자들이었던 점을 고려해 보면, 비중격 만곡증 환자들의 상당 수가 방문 당시 적극적으로 성형을 원하지는 않더라도 코 모 양에 대한 불만족을 가지고 있음을 추측해 볼 수 있다. 성형 에 대한 잠재된 욕구를 가진 환자들이 성형수술에 대한 욕 구를 표현하거나 실행하지 못하는 이유로는 성형수술에 대 한 거부감, 경제적 부담, 충분한 상담의 부재 등이 있겠고, 나 이가 많을수록 성형을 불편하게 여기는 사회적, 정서적 인식 또한 성형에 대한 접근에 장애가 될 수 있다. ${ }^{11)}$ 본 연구에서 유의한 차이는 보이지 않았지만 대조군의 평균 연령이 코 성 형군에 비해 비교적 높았던 점은 이러한 가설을 뒷받침할 수 있겠다. 이렇듯 코 성형술의 결정에는 환자 본인의 선택이 크 게 차지하기 때문에 환자들이 자신이 원하는 바를 잘 알고 선택할 수 있도록 세심한 상담이 필요하다. 그러한 맥락에서 코막힘 환자에서 $\mathrm{K}-\mathrm{SCHNOS}$ 설문지를 활용하는 것 또한 치료 계획을 세우는 데 중요한 변인이 될 것이다. 최근에 Kandathil 등 ${ }^{12)}$ 이 87명의 환자를 대상으로 시행한 코 성형수 술 전과 후의 SCHNOS 점수를 비교한 연구에서 기능 척도는 평균적으로 30.5 점의 차이를 보였고 미용 척도는 37.5 점의 차이를 보였다. 또한 임상적으로 중요하다고 판단할 수 있는 최소한의 점수 차이(minimal clinically important difference, $\mathrm{MCID})$ 를 기능 척도에서는 26.0점, 미용 척도에서는 22.1점 으로 결정하였다. 이를 통해 $\mathrm{K}-\mathrm{SCHNOS}$ 설문지를 임상에 적용한다면 코 성형수술 시행 전 환자의 기능적, 미용적 요구 파악뿐만 아니라 코 성형수술 후 환자의 만족도 평가에 유용 한 도구로 사용될 것임을 기대해 볼 수 있다. 앞으로 임상 현 장에서 SCHNOS의 유용성에 대한 검증 및 $\mathrm{K}-\mathrm{SCHNOS}$ 의 $\mathrm{MCID}$ 를 설정하는 후속 연구가 필요하겠다.

\section{Acknowledgments}

The authors thank Professor Sam. P Most for providing the Standardized Cosmesis and Health Nasal Outcomes Survey.

\section{Author Contribution}

Conceptualization: Yong Ju Jang. Data curation: Yong Ju Jang. Formal analysis: Woo Ri Choi. Investigation: Shin Ae Kim, Sung Hee Kim. Methodology: Woo Ri Choi, Yong Ju Jang. Project ad- ministration: Yong Ju Jang. Resources: Yong Ju Jang. Software: Woo Ri Choi. Supervision: Yong Ju Jang. Validation: Woo Ri Choi. Visualization: Woo Ri Choi. Writing_original draft: Woo Ri Choi. Writing—review \& editing: Yong Ju Jang.

\section{ORCID}

Yong Ju Jang https://orcid.org/0000-0001-7631-0388

\section{REFERENCES}

1) Rhee JS, Sullivan CD, Frank DO, Kimbell JS, Garcia GJ. A systematic review of patient-reported nasal obstruction scores: Defining normative and symptomatic ranges in surgical patients. JAMA Facial Plast Surg 2014;16(3):219-25.

2) Kennedy JL, Hubbard MA, Huyett P, Patrie JT, Borish L, Payne SC. Sino-nasal outcome test (SNOT-22): A predictor of postsurgical improvement in patients with chronic sinusitis. Ann Allergy Asthma Immunol 2013;111(4):246-51.

3) Schwitzer JA, Sher SR, Fan KL, Scott AM, Gamble L, Baker SB. Assessing patient-reported satisfaction with appearance and quality of life following rhinoplasty using the FACE-Q appraisal scales. Plast Reconstr Surg 2015;135(5):830e-7.

4) Alsarraf R. Outcomes research in facial plastic surgery: A review and new directions. Aesthetic Plast Surg 2000;24(3):192-7.

5) Moubayed SP, Ioannidis JPA, Saltychev M, Most SP. The 10-item Standardized Cosmesis and Health Nasal Outcomes Survey (SCHNOS) for functional and cosmetic rhinoplasty. JAMA Facial Plast Surg 2018;20(1):37-42.

6) Abdelwahab M, Saltychev M, Elkholy NA, Elsisi H, Moubayed SP, Most SP. Arabic validation of the Standardized Cosmesis and Health Nasal Outcome Survey for arabic-speaking rhinoplasty patients. Plast Reconstr Surg 2019;143(3):673e-5.

7) Rahavi-Ezabadi S, Most SP, Saltychev M, Sazgar AA, Moubayed SP, Saedi B. Validation of the persian language version of the Standardized Cosmesis and Health Nasal Outcomes Survey (SCHNOS). JAMA Facial Plast Surg 2018;20(6):521-3.

8) Atallah MR, Milad D, Benamer YH, Saltychev M, Most SP, Moubayed SP. Translation, cultural adaptation and validation of the SCHNOS in French. J Otolaryngol Head Neck Surg 2019;48(1):17.

9) Perez-Garcia IC, Peñaranda A, Cobo R, Hernandez AV, Moubayed SP, Most SP. Spanish translation, cultural adaptation, and validation of the Standardized Cosmesis and Health Nasal Outcomes Survey Questionnaire. Plast Reconstr Surg Glob Open 2019;7(3):e2153.

10) Laine C, Davidoff F, Lewis CE, Nelson EC, Nelson E, Kessler RC, et al. Important elements of outpatient care: A comparison of patients' and physicians' opinions. Ann Intern Med 1996;125(8):640-5.

11) Milothridis P, Pavlidis L, Haidich AB, Panagopoulou E. A systematic review of the factors predicting the interest in cosmetic plastic surgery. Indian J Plast Surg 2016;49(3):397-402.

12) Kandathil CK, Saltychev M, Abdelwahab M, Spataro EA, Moubayed SP, Most SP. Minimal clinically important difference of the Standardized Cosmesis and Health Nasal Outcomes Survey. Aesthet Surg J 2019;39(8):837-40. 